\title{
Antioxidant study of biaryls synthesized in the presence of Aliquat-336 activated by ultrasound
}

\author{
Said Khemais ${ }^{1}$, Houcine Labiadh ${ }^{2}$, Karima Lahbib ${ }^{3}$ and Ridha Ben Salem ${ }^{1, *}$ \\ ${ }^{1}$ Physical Organic Chemistry Laboratory (UR11ES74), Science Faculty of Sfax, 3018 Sfax, Tunisia \\ ${ }^{2}$ Unité de Recherche UR11ES30 de Synthèse et Structures de Nanomatériaux, Université de Carthage, \\ Faculté des Sciences de Bizerte, 7021 Jarzouna, Tunisia \\ ${ }^{3}$ Laboratory of Heteroatom Organic Chemistry, Faculty of Sciences of Bizerte Jarzouna 7021, Tunisia
}

\begin{abstract}
In this work we describe the study of some Suzuki coupling reactions of an aryl halide with arylboronic acids. The reaction yields obtained were increased through sonochemical activation and in the presence of a phase transfer catalyst for a very short period of time. The isolated products obtained are highly pure. In this context, we propose the reaction mechanisms for these reactions in the presence of a catalyst. The synthesized compounds were screened for their antioxidant activity using the 1,1-diphenyl-2-picrylhydrazyl (DPPH), ferric reducing power (FRP) assay and ferrous ion chelating (FIC) methods. It was found that the synthesized biaryl compounds show an enhancing antioxidant activity.
\end{abstract}

Keywords: Coupling Reactions. Nickel Catalysts. Suzuki reaction. Sonochemical activation. Ultrasound. antioxidant.

\section{Introduction}

Coupling reactions are catalyzed with a palladium compound ${ }^{1}$ or Ni-Pd bimetallic catalysts ${ }^{2}$. The use of palladium catalysts to run the homocoupling reaction of aryl halides also has been reported in the literature ${ }^{3}$. However, the relatively low yield and the requirement of drastic reaction conditions for palladium catalyzed homocoupling reactions greatly limit its practical applications in organic synthesis. On the other hand, Ni catalysts have many advantages over the Pd catalyst; for example, they are more reactive and often cheaper than the Pd complexes. Ni-catalyzed reactions are more specific and are complementary to their $\mathrm{Pd}$ analogues. Their stability in air, ease of preparation and separation of the catalyst mixture from the product at the end of the reaction sequence are some of the advantages of $\mathrm{Ni}$ catalysts which have been found to be better catalysts than their Pd counterparts given Ni's smaller size compared to $\mathrm{Pd}$ and which is the reason why $\mathrm{Ni}$ catalysts have been used for coupling. They are effective, fairly simple to use and in general tolerate well the presence of other active groups. Palladium is especially important, when compared to the other transition metals typically used in these reactions, due to its exceptional ability to form carbon-carbon bonds. The first class of reactions catalyzed by nickel is coupling reactions. Indeed, the literature is full of examples. One can,

*Corresponding author : Ridha Ben Salem

Email adress : ridha.bensalem@voila.fr

DOI : http://dx.doi.org/10.13171/mjc53/016051005/bensalem for example, perform a Kumada-Corriu coupling reaction using a nickel (II) complex ${ }^{4-6}$. However, Kumada-Corriu coupling is not the only coupling reaction that can be catalyzed using a nickel complex. In fact, the Suzuki-Miyaura coupling is also effectively catalyzed (with yields of over 90\%) by the nickel (II) complex ${ }^{7}$. Ultrasounds generally show an acoustic wave with frequencies in the 20 $100 \mathrm{MHz}$ range ${ }^{8}$. This energy is enough to spark chemical reactions. However, the use of ultrasounds produced in the middle of the cavities ${ }^{8,9}$ can generate high local temperatures and pressures ${ }^{11,12}$ or very strong electric fields ${ }^{10,12}$. In this respect, the sonication of the multiphase systems accelerates the reaction by guaranteeing a better contact between the different phases present ${ }^{13-15}$. In organic synthesis, many reactions have been re-analyzed using this unconventional activation technique. Biaryl is used as an intermediate for the production of a wide range of organic compounds (e.g. emulsifiers, optical brighteners, crop protection products, plastics), as a heat transfer medium alone or with diphenyl ether in heating fluids, as a dyestuff carrier for textiles and copying paper and as a solvent in pharmaceutical production. Aminodiaryls are used as rubber antioxidants and intermediates for the synthesis of organic compounds ${ }^{16}$. Biaryl derivatives are used as an intermediate for the synthesis of organic compounds including pharmaceuticals, antifungal agents ${ }^{17}$, optical brightening agents and dyes ${ }^{18}$. Biayl

Received February $23^{\text {rd }}, 2016$

Accepted April $11^{\text {th }}, 2016$

Published May 10 ${ }^{\text {th }}, 2016$ 
(biphenyl) compounds are also used in luminescence chemistry, spectrophotometric analysis, molecular chemistry, and as a starting material for organometallic complexes ${ }^{19}$. In search of inexpensive and environmentally benign catalysts, tetraalkylammonium salts have been tested alternatively as catalysts for the Heck reaction ${ }^{20,21}$ in $\mathrm{DMF} /$ water. In this paper, we have reported the synthesis of biaryl by Suzuki reaction in aqueous potassium carbonate under phase transfer catalysis using methyltrioctylammonium chloride (Aliquat336) as phase transfer agent.

We also propose the study of the effect of the catalytic system and the ultrasonic activation on the evolution of the Suzuki coupling reaction to synthesize biaryls in the presence of Aliquat-336. The synthesized compounds were screened for their antioxidant activity.

\section{Experimental Section}

\section{General procedure}

\section{Classical procedure without ultrasound}

The aryl halide (0.5 mmol), Aliquat-336 (1.25 $\mathrm{mmol})$, aryl boronic acid $(0.75 \mathrm{mmol}), \mathrm{K}_{2} \mathrm{CO}_{3}(1.0$ $\mathrm{mmol})$ and the catalyst $\mathrm{Ni}(\mathrm{OAc})_{2}(0.02 \mathrm{mmol})$ were placed in a Schlenk tube. Vacuum was applied for 30 min, and then argon was admitted. Water $(1.5 \mathrm{~mL})$ and $\mathrm{N}, \mathrm{N}$-dimethylformamide $(1.5 \mathrm{~mL})$ were added. The reaction was carried out at $100{ }^{\circ} \mathrm{C}$ for $5 \mathrm{~h}$. After reaction, the mixture was cooled and the organic phase extracted (three times) with Hexane/Water (5:1). The extraction was dried on $\mathrm{MgSO}_{4}$ and the solvent removed under vacuum. The coupling product was finally isolated by silica gel chromatography.

\section{Ultrasonic irradiation}

The ultrasonic probe was directly immersed in the reactor. An ultrasonic generator (Sonics VC 505 $300 \mathrm{~W}$ ) emits the sound vibration into the reaction mixture. Sonification was achieved at low frequencies of $20 \mathrm{kHz}$ (amplitude of $50 \%$ ) at room temperature for $5 \mathrm{~min}$. The aryl halide $(0.5 \mathrm{mmol})$, Aliquat-336 (1.25 mmol), boronic acid $(0.75 \mathrm{mmol})$, $\mathrm{K}_{2} \mathrm{CO}_{3}(1.0 \mathrm{mmol})$ and the catalyst $\mathrm{Ni}(\mathrm{OAc})_{2}(0.02$ $\mathrm{mmol})$ were placed in a reactor. Water $(1.5 \mathrm{~mL})$ and $\mathrm{N}$, N-dimethylformamide $(1.5 \mathrm{~mL})$ were added. After reaction, the mixture was extracted (three times) with Hexane/Water (5:1). The extraction was dried on $\mathrm{MgSO}_{4}$ and the solvent removed under vacuum. The coupling product was finally isolated by silica gel chromatography.
The yields of the reactions were determined by gas chromatography on a Shimadzu 2014-GC apparatus. The capillary column was DB-5 and the carrier gas was helium.

\section{Characterization}

All compounds were characterized by IR, ${ }^{1} \mathrm{H}$ NMR spectra, ${ }^{13} \mathrm{C}$ NMR spectra and mass spectra. The IR spectra were recorded in $\mathrm{KBr}$ with a JASCO FT-IR-420 spectrometer, with a precision of $\pm 2 \mathrm{~cm}^{-1}$ in the $400-4000 \mathrm{~cm}^{-1}$ range. The $1 \mathrm{H}$ NMR spectra (400 MHz) and ${ }^{13} \mathrm{C}$ NMR spectra $(100 \mathrm{MHz})$ were obtained on a Bruker AC300 spectrometer using $\mathrm{CDCl}_{3}$ as solvent and TMS as an internal standard. Chemical shifts are given in ppm.

The coupling products were analyzed by GC-MS (Hewlett-Packard computerized system consisting of a 5890 gas chromatograph coupled to a 5971A mass spectrometer using fused-silica capillary columns with polar stationary phase: Supelcowax 10 (60 m$0.2 \mathrm{~mm}-0.20 \mathrm{~lm}$ film thickness). GC-MS analyses were obtained using the following conditions: carrier gas $\mathrm{He}$; flow rate $1 \mathrm{ml} / \mathrm{min}$; split 1:20; injection volume $0.1 \mu \mathrm{l}$; injection temperature $250{ }^{\circ} \mathrm{C}$; oven temperature programmed from 60 to $220^{\circ} \mathrm{C}$ at 4 $\mathrm{C} / \mathrm{min}$ and holding at $220^{\circ} \mathrm{C}$ for $30 \mathrm{~min}$; the ionization mode used was electronic impact at 70 $\mathrm{eV}$.

PL spectra were measured on a $\mathrm{C}_{6} \mathrm{PbI}_{4}$ thin film using a double monochromator U1000 equipped with a photomultiplier. The excitation wavelength was the $325 \mathrm{~nm}(3.815 \mathrm{eV})$ line of a Spectra-Physics beamlock 2085 argon laser.

Melting points were recorded on a ReichertHeizbank apparatus.

\section{Results and Discussion}

\section{Chemistry}

In this work, the study of some Suzuki reactions was analyzed using aryl halides and arylboronic acids. The isolated product was formed by magnetic stirring and in ultrasonic radiation in the presence of a phase transfer catalyst.

The selection of the solvent in a sonochemical reaction is crucial because the cavitation intensity varies with the solvent and depends on its nature. The intensity of cavitation in water is always a maximum and the cavitation intensity in other solvents is compared to that in water ${ }^{22}$. The effect of solvents and adding water as the co-solvent on the coupling Suzuki reaction (Table 1) was studied. 
Table1. Effect of different solvents on the Suzuki reaction in the presence of ultrasound

\begin{tabular}{|c|c|c|c|c|}
\hline Entry & Solvent & $\varepsilon$ to $25^{\circ} \mathrm{C}$ & $\mu\left(10^{-30} \mathrm{~cm}^{-1}\right)$ & Yield $(\%)^{\mathbf{b}}$ \\
\hline 1 & Toluene & 2.38 & 11.20 & 5 \\
\hline 2 & THF & 7.58 & 5.90 & 13 \\
\hline 3 & $\mathrm{CH}_{3} \mathrm{CN}$ & 35.94 & 5.70 & 26 \\
\hline 4 & $\mathrm{H}_{2} \mathrm{O}$ & 87 & 0.00 & 90 \\
\hline 5 & DMF & 36.7 & 10.80 & 55 \\
\hline 6 & DMA & 37.8 & 2.82 & 40 \\
\hline 7 & NMP & 15.45 & 4.09 & 45 \\
\hline 8 & DMSO & 46.7 & 4.3 & 50 \\
\hline 9 & $\mathrm{MeOH}$ & 32.7 & 1.71 & 3 \\
\hline 10 & $\mathrm{H}_{2} \mathrm{O} / \mathrm{DMF}(1: 1)$ & - & - & 97 \\
\hline 11 & $\mathrm{H}_{2} \mathrm{O} / \mathrm{DMF}(1: 4)$ & - & - & 85 \\
\hline 12 & $\mathrm{MeOH} / \mathrm{H}_{2} \mathrm{O}(1: 1)$ & - & - & 65 \\
\hline
\end{tabular}

${ }^{\mathrm{a}}$ Reaction conditions: $(0.5 \mathrm{mmol})$ of bromobenzene $(0.75 \mathrm{mmol})$ of phenylboronic acid $(1 \mathrm{mmol})$ of $\mathrm{K}_{2} \mathrm{CO}_{3}$, $(0.05 \mathrm{~mol} \%)$ of $\mathrm{Ni}(\mathrm{OAc})_{2}$.

${ }^{\mathrm{b}}$ Conversion to coupled product determined by GC, based on aryl halides; average of two runs.

These results showed a conversion of $40-50 \%$ after $15 \mathrm{~min}$ for the reaction of polar aprotic solvents such as N,N-dimethylformamide (DMF), N, Ndimethylacetamide (DMA), N-methylpyrrolidone (NMP) and dimethylsulfoxide (DMSO) (Table 1, entries 1-4). The reaction in ethereal, alcoholic, and non-polar solvents was sluggish (Table 1, entries 1, 2 and 9). However, the addition of water as a polar cosolvent to the aprotic solvents greatly improved the rate of reaction. The addition of water to DMF led to a very rapid increase in the reaction rate: the reaction was complete after 5 minutes and 8 minutes when the water to DMF ratios were 1: 1 and 1: 4 respectively (Table 1, entries 10,11). The results suggest that the water to DMF ratio plays an important role in the $\mathrm{Ni}$ (II)-catalyzed Suzuki reaction.

Table 2. Effect of different bases on the Suzuki reaction

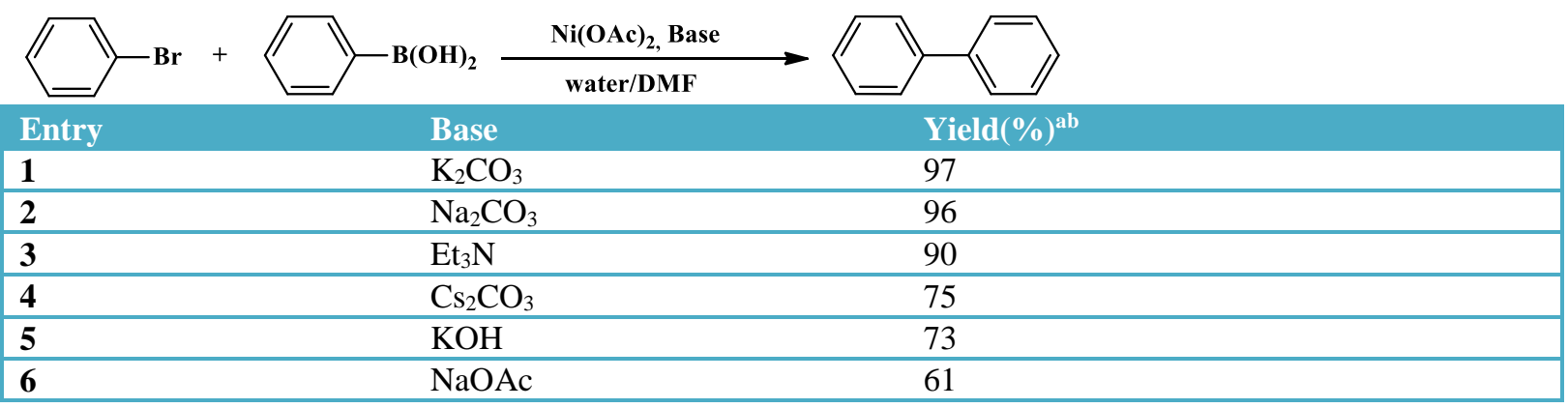

${ }^{\mathrm{a}}$ Reaction conditions: $(0.5 \mathrm{mmol})$ of bromobenzene, $(0.75 \mathrm{mmol})$ of

phenylboronic, $(1 \mathrm{mmol})$ of base, $(0.05 \mathrm{~mol} \%)$ of $\mathrm{Ni}(\mathrm{OAc})_{2},(1.5 \mathrm{~mL})$ of water and $(1.5 \mathrm{~mL})$ of $\mathrm{DMF}, 5 \mathrm{~h}, 100^{\circ} \mathrm{C}$.

${ }^{\mathrm{b}}$ Conversion to coupled product determined by GC, based on aryl halides; Average of two runs.

To examine the effect of a base on the reaction, a series of bases were used for the coupling between bromobenzene and phenylboronic acid. The most common and inexpensive bases, such as $\mathrm{K}_{2} \mathrm{CO}_{3}$, $\mathrm{Na}_{2} \mathrm{CO}_{3}$ and $\mathrm{Et}_{3} \mathrm{~N}$, were found to be more effective (Table 2). Surprisingly, $\mathrm{Cs}_{2} \mathrm{CO}_{3}$ was found to be less effective in the present system although it is a common base for several nickel Suzuki reactions ${ }^{23,24}$. Similarly, it was found that the commonly used $\mathrm{NaOAc}$ was also less effective in the studies performed although it is an efficient base for $\mathrm{Pd} / \mathrm{NiFe}_{2} \mathrm{O}_{5}$ Suzuki-type catalytic reactions ${ }^{25}$. This may be due to the relatively lower basic nature of phosphinite compared to phosphines.
The reaction mechanism starts with the reduction of the $\mathrm{Ni}$ (II) precursor to form $\mathrm{Ni}(0)$. It turns out that the presence of Aliquat-336 plays an important role in the reduction of nickel (II) and in the stabilization and solubilization of nickel (0). During the reaction process, several reduction and oxidation catalytic cycles of palladium take place. The solubilization is provided by the formation of an $\left[\mathrm{R}_{4} \mathrm{~N}\right]_{2}\left[\mathrm{NiArBrCl}_{2}\right]$-type ionic complex. The formation of this complex leads to the release of an $\mathrm{R}_{3} \mathrm{~N}$ amine which plays the basic role required to finish the catalytic cycle of the Suzuki reaction. 


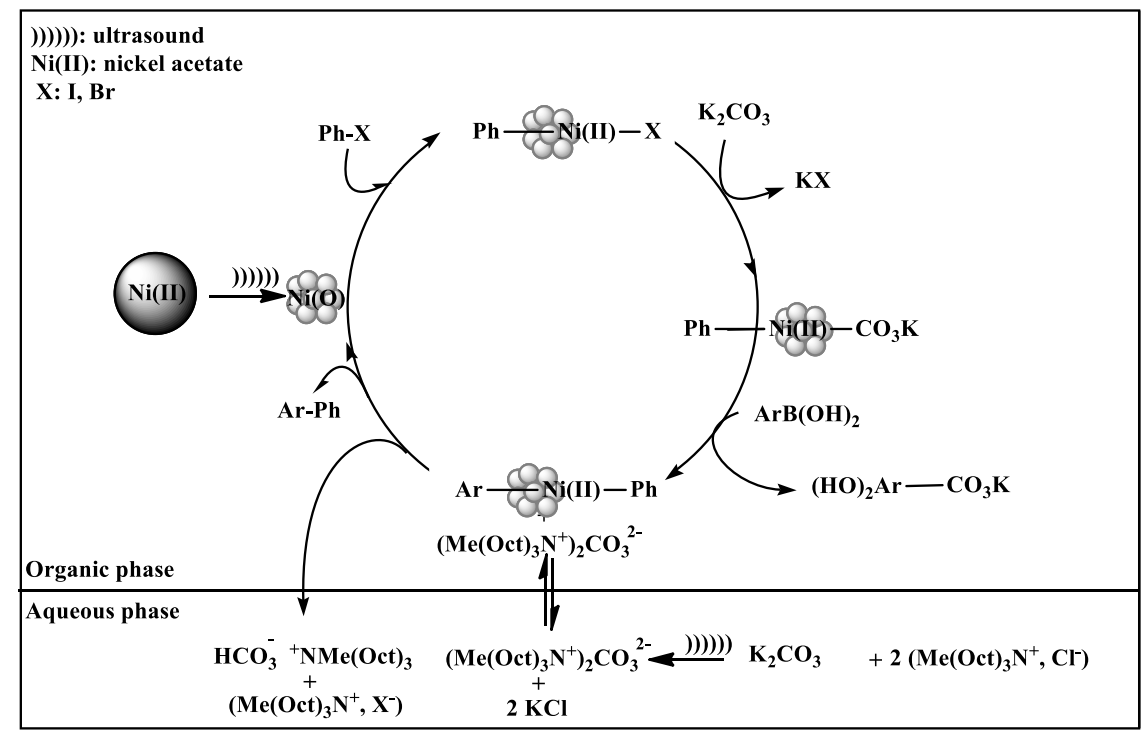

Figure 1. Sonochemical activation of Suzuki coupling in the presence of Aliquat-336

In order to increase the yield of the Suzuki coupling reaction, bi-activation with the Aliquat-336 phase transfer catalyst bias associated with ultrasonic radiation was used.

Table 3. Suzuki coupling of aryl halides and various arylboronic acids<smiles>[X]c1ccc([X])cc1</smiles>

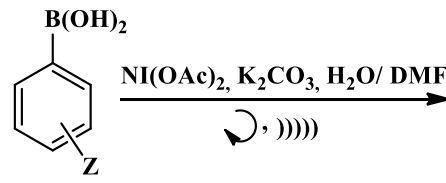<smiles>[Y][Y]1cccc(-c2ccc([Y])cc2)c1</smiles>

\begin{tabular}{|c|c|c|c|c|c|c|c|}
\hline Entry & $\mathbf{X}$ & $\mathbf{Y}$ & $\mathbf{Z}$ & $\begin{array}{l}\text { Coupling } \\
\text { product }\end{array}$ & Lit. & Yield $(\%)^{\text {ac }}$ & Yield $(\%)^{b c}$ \\
\hline 1 & I & $\mathrm{H}$ & $\mathrm{H}$ & $1 \mathrm{a}$ & 35,36 & 78 & 91 \\
\hline 2 & I & 4-Me & $\mathrm{H}$ & $1 \mathrm{a}$ & 35,36 & 75 & 87 \\
\hline 3 & $\mathrm{Br}$ & 4-Me & $\mathrm{H}$ & $2 \mathrm{a}$ & 35,36 & 70 & 82 \\
\hline 4 & $\mathrm{Br}$ & 4-OMe & $\mathrm{H}$ & $3 a$ & $35,36,37$ & 74 & 87 \\
\hline 5 & $\mathrm{Br}$ & 3-OMe & $\mathrm{H}$ & $4 a$ & 35 & 71 & 82 \\
\hline 6 & $\mathrm{Br}$ & 2-OMe & $\mathrm{H}$ & $5 a$ & 35 & 71 & 77 \\
\hline 7 & $\mathrm{Br}$ & 2-Me & $\mathrm{H}$ & $6 a$ & 35 & 62 & 72 \\
\hline 8 & $\mathrm{Br}$ & 4-CHO & $\mathrm{H}$ & $7 \mathrm{a}$ & 40 & 70 & 80 \\
\hline 9 & $\mathrm{Br}$ & $4-\mathrm{CN}$ & $\mathrm{H}$ & $8 \mathrm{a}$ & 42 & 74 & 86 \\
\hline 10 & $\mathrm{Rr}$ & $4-\mathrm{NO}_{2}$ & $\mathrm{H}$ & $9 \mathrm{a}$ & 35 & 74 & 88 \\
\hline 11 & $\mathrm{Br}$ & 4-OMe & 4-OMe & $10 \mathrm{a}$ & 37 & 69 & 85 \\
\hline 12 & $\mathrm{Br}$ & 4-Me & 4-Me & $11 \mathrm{a}$ & 38 & 74 & 88 \\
\hline 13 & $\mathrm{Br}$ & $4-\mathrm{CN}$ & $4-\mathrm{CN}$ & $12 \mathrm{a}$ & 38 & 68 & 83 \\
\hline 14 & $\mathrm{Br}$ & 2-Me & 2-Me & $13 a$ & 41 & 60 & 75 \\
\hline 15 & $\mathrm{Br}$ & 4-Cl & $4-\mathrm{Cl}$ & $14 a$ & 38 & 74 & 90 \\
\hline 16 & $\mathrm{Br}$ & 4-COMe & $\mathrm{H}$ & $15 a$ & 35 & 78 & 91 \\
\hline 17 & $\mathrm{Br}$ & 3-COMe & $\mathrm{H}$ & $16 a$ & 35 & 70 & 86 \\
\hline 18 & $\mathrm{Br}$ & 2-COMe & $\mathrm{H}$ & $17 \mathrm{a}$ & 41 & 65 & 83 \\
\hline
\end{tabular}

a Reaction conditions: Catalyst $(0.02 \mathrm{mmol})$, Aliquat-336 $(1.25 \mathrm{mmol})$, aryl halide, $(0.5 \mathrm{mmol})$ arylboronic acid $(0.75 \mathrm{mmol}) \mathrm{K}_{2} \mathrm{CO}_{3},(1 \mathrm{mmol})$, water $(1.5 \mathrm{~mL})$, DMF $(1.5 \mathrm{~mL}), 5 \mathrm{~h}, 100^{\circ} \mathrm{C}$

${ }^{\mathrm{b}}$ Catalyst $(0.02 \mathrm{mmol})$, Aliquat-336 $(1.25 \mathrm{mmol}$ aryl halide, $(0.5 \mathrm{mmol})$ arylboronic acid,

$(0.75 \mathrm{mmol}), \mathrm{K}_{2} \mathrm{CO}_{3}(1 \mathrm{mmol})$, water $(1.5 \mathrm{~mL}), \mathrm{DMF}(1.5 \mathrm{~mL})$, ultrasonic irradiation $5 \mathrm{~min}$

${ }^{c}$ All isolated yields, average of two runs

In this context, the results shown in Table 3 highlight that under optimized conditions at room temperature, the coupling of aryl halides with nickel catalyzed arylboronic acids, where they are activated by the Aliquat-336 phase transfer catalyst under ultrasonic radiation, tend to improve the yield compared to conventional conditions. For example, adding the Aliquat-336 phase transfer catalyst leads to a remarkable activity (Table 3 ) which improves the yield ${ }^{20,21,26,27}$. The positive effect of ultrasound on the yield of the coupling halides with aryl boronic acids bearing different substituents has also been 
demonstrated. The effect of the substituents of the aryl boronic acid in this reaction has been investigated. The p-bromotoluene reacts with a set of aryl boronic acids which produces the corresponding biphenyl with moderate to excellent conversions (entries 2, 3, 12, 87, 82, 88\%). This process was also tolerant of ortho-substituents as evidenced by the successful coupling of phenylboronic acid with 2bromotoluene (entries 7, 14, 72, 75\%). As for the non-activated substrate p-bromoanisole, the use of deactivated electron rich aryl bromide (e.g. entry 4, 11) as well as activated, electron-poor ones (entries $8-10,13$ and 16) also resulted in high yields ${ }^{28}$. Generally, these coupling reactions can be satisfactorily carried out at room temperature.

\section{Biological activity}

All analyses were performed using a $U V$ spectrophotometer (6005). The result is presented as $\mathrm{IC}_{50}$ (the concentration of test product required for scavenging $50 \%$ of the radical).

\section{Statistical analysis}

Results are expressed as the mean \pm standard error of the mean (SEM). Statistical differences were evaluated by one-way analysis of variance (ANOVA) followed by Turkey's HSD test when significant differences were observed $(\mathrm{p}<0.05)$.

All analyses were performed using STATISTICA version 5.00 (Stat Soft- France, Tulsa, OK, USA) for Windows.

\section{DPPH radical scavenging activity}

The most common methods for determining antioxidant activity in a practical, rapid and accurate manner are those that involve a radical chromophore, simulating the reactive oxygen species (ROS). The free radical DPPH, purple in color that absorbs at $517 \mathrm{~nm}$, is one of the most widely used radical chromophores for in vitro evaluation of antioxidant activity. The DPPH radical scavenging assay employed here is as described by Braca et $\mathrm{al}^{29}$.

The reduction capability of the DPPH radical is determined by the decrease in absorbance at $517 \mathrm{~nm}$ induced by antioxidants. Ascorbic acid (AA) is the reagent used as standard. The sample is able to reduce the stable radical DPPH to the yellow-colored diphenylpicrylhydrazine. Experimentally, various dilutions of the compound methanolic solution or standard $(0.001-1 \mathrm{mg} / \mathrm{mL}$, in triplicate) were added to the DPPH solution $(0.035 \mathrm{mg} / \mathrm{mL})$. The absorbance of the mixture was taken at $517 \mathrm{~nm}$ with methanol as blank. A control sample with no added test compounds was also analyzed. Radical scavenging activity was expressed as a percentage and calculated using the formula: \% Scavenging = [(Acont - Atest)/Acont] * 100, where Acont is the absorbance of the control, and Atest is the absorbance of the sample in the presence of the test compound. The result was presented as $\mathrm{IC}_{50}$ (the concentration of test compound required for scavenging $50 \%$ of the DPPH radical). It was found that the aryl compound has a DPPH radical scavenging activity with an $\mathrm{IC}_{50}$ of $3.644 \pm 0.018$ $\mathrm{mg} / \mathrm{mL}$ compared to ascorbic acid $\left(\mathrm{IC}_{50}: 0.039 \pm\right.$ $0.002 \mathrm{mg} / \mathrm{mL}$ ), Figure 3 .

\section{Ferric reducing power (FRP)}

A direct correlation has been observed between the antioxidant activity and reducing power of certain compounds. The reducing power of the extract was determined according to the method of Oyaizu $^{30}$ and compared with that of ascorbic acid. Substances which have a reducing potential, react with potassium ferricyanide $\left(\mathrm{Fe}^{3+}\right)$ to form potassium ferrocyanide $\left(\mathrm{Fe}^{2+}\right)$, which then reacts with ferric chloride to form a ferric ferrous complex that has a maximum absorption at $700 \mathrm{~nm}$. Experimentally, a methanolic solution of the compounds $(1 \mathrm{~mL})$ at various concentrations $(0.001-1 \mathrm{mg} / \mathrm{mL})$ was mixed with a phosphate buffer $(0.2 \mathrm{M})$ and potassium ferricyanide $(1 \%)$. The mixture was incubated at 50 ${ }^{\circ} \mathrm{C}$ for $20 \mathrm{~min}$. Aliquots of trichloroacetic acid (10\%) were added to the mixture, which was then centrifuged at $3000 \mathrm{rpm}$ for $10 \mathrm{~min}$. The upper layer $(2.5 \mathrm{~mL})$ was mixed with distilled water and a freshly-prepared ferric chloride solution $(0.1 \%)$. The absorbance was measured at $700 \mathrm{~nm}$. Ascorbic acid was used as standard. A control sample was prepared without adding a standard or test compound. Increased absorbance of the reaction mixture indicates an increase in reducing power. The percentage increase in the reducing power was calculated using the following formula: Increase in reducing power $(\%)=[($ Atest - Acont $) /$ Acont $] * 100$, where Atest is the absorbance of the sample in the presence of the compound and Acont is the absorbance of the control. The result was expressed as $\mathrm{IC}_{50}$ which corresponds to the concentration of the extract necessary to reduce $50 \%$ of the ferric ferrous complex. The results show that the aryl compound showed a good reducing power with $\mathrm{IC}_{50}$ at $1.12 \pm$ $0.016 \mathrm{mg} / \mathrm{mL}$ compared to the ascorbic acid $\left(\mathrm{IC}_{50}: 0.0035 \pm 0.00004 \mathrm{mg} / \mathrm{mL}\right)$, Figure 3 .

\section{Ferrous ion chelating (FIC) activity}

It has been reported that chelating agents are effective as secondary antioxidants because they reduce the redox potential thereby stabilizing the oxidized form of the metal ion.

The FIC ability of the extract was determined according to the method of Singh and Rajini ${ }^{31}$. A methanolic solution of the test compound $(1.0 \mathrm{~mL})$ at various concentrations $(0.001-1 \mathrm{mg} / \mathrm{mL})$ was added to $1.0 \mathrm{~mL}$ of $\mathrm{FeSO}_{4}(0.1 \mathrm{mM})$ and $1.0 \mathrm{~mL}$ of ferrozine $(0.25 \mathrm{mM})$. The tubes were shaken well and left to stand for $10 \mathrm{~min}$. The absorbance was measured at $562 \mathrm{~nm}$. The ability of each sample to chelate ferrous ions was calculated relative to the control consisting of only iron ferrozine, using the following formula: \% FIC $=$ [(Acont- Atest $) /$ Acont $]$ $* 100$, where Acont is the absorbance of the control, and Atest is the absorbance of the sample in the presence of the compound. 
The aryl compound showed a high ferrous ion chelating ability with $\mathrm{IC}_{50}$ at $2.40 \pm 0.18 \mathrm{mg} / \mathrm{mL}$

compared to the ascorbic acid $\left(\mathrm{IC}_{50}: 0.0057 \pm 0.0002\right.$ $\mathrm{mg} / \mathrm{mL}$ ), Figure 3.

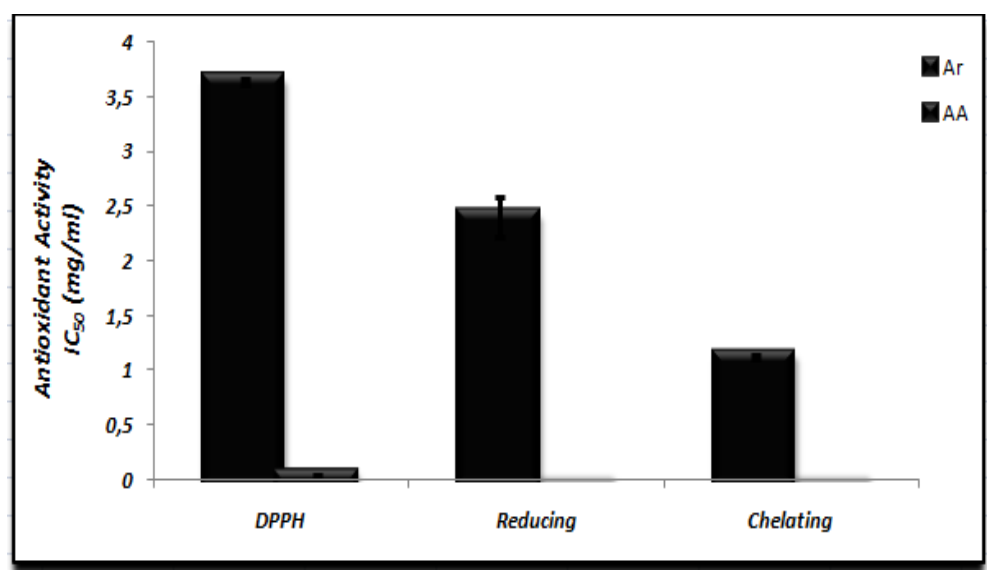

Figure 3. Antioxidant activity of biaryl-synthesized compounds (Ar: biaryl, AA: Ascorbic acid, $\mathrm{IC}_{50} \mathrm{mg} / \mathrm{mL}$ )

These results have made the link between the synthesized Biaryl compounds and antioxidant activities. They have opened the way to analyzing the complex relationship between free iron and ROS which are responsible for the oxidation of key proteins involved in signal transduction of apoptosis.

It was found that biphenyl compounds show an enhancing antioxidant activity with the DPPH, FRP and FIC methods. These results are further confirmed by those of El-Wakil et al. $(2006)^{32}$, which show that the presence of aminodiphenyl groups could enhance antioxidant proprieties. This biological activity has also been highlighted by the presence of a hydroxyl group in the aromatic ring which could be an electron donor to exert direct antioxidant activity by the scavenging effect ${ }^{33}$. These results also emphasize the ability of biaryl compounds, as iron chelators, to exert a secondary antioxidant effect by chelating the bivalent iron necessary for the formation of hydroxyl radicals and preventing the Fenton reaction ${ }^{34}$.

\section{Conclusions}

Firstly, Ni (II) in the presence of Aliquat-336 has been studied in a water-DMF mixture showing high catalytic activity in the Suzuki reaction with short reaction times. Secondly, the ability of the synthesized biaryl compounds as antioxidant agents has been studied using different in vitro methods. It has been found that biphenyl compounds show an enhancing antioxidant activity.

\section{Acknowledgements}

We greatly acknowledge the financial support of the Ministry of Higher Education and Scientific Research of Tunisia.

\section{Experimental Section}

All spectral data and melting points of synthesized compounds compare favourably with those cited in the literature (Table 3 ).

\section{References}

1- L. Shen, S. Huang, Y. Nie, F. Lei, An Efficient Microwave-Assisted Suzuki Reaction using a New Pyridine-Pyrazole/Pd(II) Species as Catalyst in Aqueous Media, Molecules, 2013, 18, 1602-612.

2- R. Narayanan, Recent Advances in Noble Metal Nanocatalysts for Suzuki and Heck CrossCoupling Reactions, Molecules, 2010, 15, 2124-2138.

3- F. T. Luo, A. Jeevanandam, M. K. Basu, F.T. Luo and others, Efficient and High Turnover Homocoupling reaction of aryl iodide by the use of palladacycle -A convenient way to prepare poly-pphenylene, , Tetrahedron Lett., 1998, 39, 7939

4- F. Hu, B. N. Kumpati, X. Lei, Diaminophosphine oxides as preligands for Ni-catalyzed Suzuki cross-coupling reactions of aryl chlorides with arylboronic acids, Tetrahedron Letters, 2014, 55, 7215-7218.

5- M. Wang, X. Yuan, H. Li, L. Ren, Z. Sun, Y. Hou, W. Chu, Nickel-catalysed Suzuki-Miyaura cross-coupling reactions of aryl halides with arylboronic acids in ionic liquids, Catalysis Communications, 2015, 58, 154-157.

6- T. Zell, P. Fischer, D. Schmidt, U. Radius, C-Br Activation of Aryl Bromides at $\mathrm{NiO}(\mathrm{NHC})_{2}$ : Stoichiometric Reactions, Catalytic Application in Suzuki-Miyaura Cross-Coupling, and Catalyst Degradation, Organometallics, 2012, 31, 5065-5073.

7- C.Y. Liao, K.T. Chan, Y.C. Chang, C.Y. Chen, C.Y. Tu, C.H. Hu, H.M. Lee, Unexpected solvent-induced cis/trans isomerization and catalytic application of a bis-bidentate nickel(II) complex with N-heterocyclic carbene and amido functionalities, Organometallics, 2007, 26, 5826-5833.

8- F. Alonso, I.P. Beletskaya, M. Yus, Nonconventional methodologies for transition-metal catalysed carbon-carbon coupling: a critical 
overview. Part 1: The Heck reaction, Tetrahedron, 2005, 61, 11771-11835.

9- J.P. Lorimer, T.J. Mason, Sonochemistry. Part 1the physical aspects, Chem. Soc. Rev., 1987, 16, 239-274.

10- T. Lepoint, F. Mullie, What exactly is cavitation chemistry, Ultrason. Sonochem., 1994, 1, S13-S22.

11- T.J. Mason, J.P. Lorimer, Applied Sonochemistry. The Uses of Power Ultrasound in Chemistry and Processing, Wiley-VCH 2002.

12- M.A. Margulis, Sonochemistry as a New Promising Area of High Energy Chemistry, Chem. 2004, 38, 135-142.

13- G.V. Ambulgekar, B.M. Bhanage, S.D. Samant, Low temperature recyclable catalyst for Heck reactions using ultrasound, Tetrahedron Lett., 2005, 46, 2483-2485.

14- M. Atobe, Y. Kado, R. Asami, T. Fuchigami, T. Nonaka, Ultrasonic effects on electroorganic processes. Part 25. Stereoselectivity control in cathodic debromination of stilbenedibromides, Ultrason. Sonochem., 2005, 12, 1-5.

15- K. Bougrin, M. Lamiri, M. Soufiaoui, Synthèse "One pot" de Dérivés Isoxazoliniques par Activation

Sonochimique, Tetrahedron Lett., 1998, 39, 4455-4458.

16- International Agency for Research on Cancer: Lyon. IARC Monographs on the Evaluation of the arcinogenic Risk of Chemicals to Man" 1972, 1, 74-79.

17- G.C. Porretta , R. Fioravanti, M. Biava, M. Artico, A. Villa, N. Simonetti, Antifungal agents, Part 11. Biphenyl analogues of naftifine: synthesis and antifungal activities, Arch Pharm (Weinheim), 1995, 328, 667-672.

18- A. Daniel Jervis Optical brighteners: improving the colour of plastecs. Plastics, A. Jervis impoving the colour of plastec, 2003, 5, 423-46.

19- A. D. Hunter, D. Ristic-Petrovic, J. L. McLernon, Organometallic complexes with electronic bridges. 8. Biphenyl-, terphenyl-, naphthalene-, and anthracene-bridged bi- and trimetallic complexes of iron and chromium, Organometallics, 1992, 11, 864-871.

20- K. Saïd, Y. Moussaoui, M. Kammoun, R. Ben Salem, Ultrasonic activation of Heck type reactions in the presence of Aliquat-336, Ultrasonics Sonochemistry, 2011, 18, 8-27.

21- K. Saïd, Y. Moussaoui, R. Ben Salem, Heck Coupling Styrene with aryl halides Catalyzed by palladium Complexes in Biphasic Media, J. Soc. Chim. Tunisie, 2009, 11, 59-67.

22- M. Oyaizu, Studies on products of the browning reaction. Antioxidative activities of browning reaction products prepared from glucosamine, Japanese Journal of Nutrition, 1986, 44, 307-315.

23- A. Braca, N. D. Tommasi, L.D. Bari, C. Pizza, M. Politi, I. Morelli. Antioxidant principles from
Bauhinia Tarapotensis, J. Nat. Prod., 2001, 64, 892-895.

24- M. A. Margulis, High Energ. Sonochemistry as a New Promising Area of High Energy Chemistry, Chem. 2004, 38, 135-142.

25- N. Miyaura, A. Suzuki, Palladium-Catalyzed Cross-Coupling Reactions of Organoboron Compounds, Chem. Rev., 1995, 95, 2457-2483.

26- A. Suzuki, Cross-coupling Reactions of Organoboron Compounds with Organic Halides. In: Diederich F, Stang P J, editors. MetalCatalyzed Cross-Coupling Reactions. Weinheim, Germany: Wiley- $\mathrm{VCH}$; 1998, 49-89.

27- RS. R. Borhade, S. B. Waghmode, Studies on $\mathrm{Pd} / \mathrm{NiFe}_{2} \mathrm{O}_{4}$ catalyzed ligand-free Suzuki reaction in aqueous phase: synthesis of biaryls, terphenyls and polyaryls, Beilstein J Org Chem., 2011, 7, 310-319.

28- D. Pandiarajan, R. Ramesh, Y. Liu, R. Suresh, Palladium(II) thiosemicarbazone-catalyzed Suzuki-Miyaura cross-coupling reactions of aryl halides, Inorganic Chemistry Communications, 2013, 33, 33-37.

29- L. Mhamdi, K. Saïd, Y. Moussaoui, R. Ben Salem, Biactivation de la réaction de Sonogashira par la catalyse par transfert de phase et sous irradiation ultrasonique, J. Soc. Chim. Tunisie, 2013, 15, 149-162.

30- Y. Moussaoui, K. Saïd, R. Ben Salem, Anionic activation of the Wittig reaction using a solidliquid phase transfer: examination of the medium-, temperature-, base- and phase-transfer catalyst effects, Arkivoc, 2006, xii, 1-22.

31- N. Singh, P.S. Rajini, Free scavenging activity of an aqueous extract of potato pell, Food Chemistry, 2004, 85, 611-616.

32- A.A El-Wakil, Synthesis, characterization, and evaluation of natural rubber-graft- $\mathrm{N}$-(4-Aminodiphenyl methane) acrylamide as an antioxidant, J Appl Polym Sci, 2006, 101, 843-849.

33- A. Joe Vinson, Y. Hao , X. Su, J. Agric, Phenol Antioxidant Quantity and Quality in Foods: Vegetables Food Chem., 1998, 46, 3 630-3634.

34- E.J. Dombrecht, P. Cos, D.V. Berghe, J.F. Van Offel, A.J. Schuerwegh, C.H. Bridts, W.J. Stevens, L.S. De lerck, Selective in vitro antioxidant properties of bisphosphonates, Biochem Biophys Res Commun. 2004, 314, 675-680.

35- H. J. Li, W. J. Liu, Y. X. X.ie, Recyclage and reusable $\mathrm{Pd}(\mathrm{OAc})_{2} / \mathrm{DABCO} / \mathrm{PEG}-400$ system for Susuki-Miyaurama cross-coupling reaction, J. Org. Chem., 2005, 70, 5409-5412.

36- J. Lemo, K. Heuzé, D. Astruc, Efficient Dendritic Diphosphino Pd(II) Catalysts for the Suzuki Reaction of Choroarene, Org. Letters, 2005, 7, 2253-2256.

37- L. Zhu, J. Duquette, M. Zhang, An Improved Preparation of Arylboronates: Application in 
One-Pot Suzuki Biaryl Synthesis, J. Org. Chem., 2003, 68, 3729-3732.

38- G. Alvarenga, C. P. Ruas, J. R. M. Vicenti, F. A. Duarte, M. A. Gelesky, G. R. Rosa, $\mathrm{PdCl}_{2}$ Immobilized in Polyacrylamide: a Low Cost and Eco-Friendly Catalyst for Suzuki-Miyaura Reactions, J. Braz. Chem. Soc., 2016, 27, 787-793.

39- Said, K. and Salem, R.B. (2016) Ultrasonic Activation of Suzuki and Hiyama CrossCoupling Reactions Catalyzed by Palladium. Advances in Chemical Engineering and Science, $6,111-123$ http://dx.doi.org/10.4236/aces.2016.62013 Tetrahedron Letters, 2005, 46, 15-18.
40- N. Kataoka, Q. Shelby,J. P. Stambuli, J. F. Hartwig, Air stable, sterically hindered ferrocenyl dialkylphosphines for palladium-catalyzed C-C, $\mathrm{C}-\mathrm{N}$, and $\mathrm{C}-\mathrm{O}$ bond-forming cross-couplings. J. Org. Chem., 2002. 67, 5553-5566.

41- A. Mukherjee, A. Sarkar, New pyrazole-tethered Schiffs bases as ligands for the Suzuki reaction, Tetrahedron Letters, 2005, 46, 15-18.

42- L. Jiang, F. Shan, Z. Li, D. Zhao, SuzukiMiyaura Reactions Catalyzed by $C 2$-Symmetric Pd-Multi-Dentate $N$-Heterocyclic Carbene Complexes, Molecules 2012, 17, 12121-12139.

42- L. Jiang, F. Shan, Z. Li, D. Zhao, SuzukiMiyaura Reactions Catalyzed by $C 2$-Symmetric Pd-Multi-Dentate $N$-Heterocyclic Carbene Complexes, Molecules 2012, 17, 12121-12139. 